\title{
Comparando Mesoamérica y los Andes a través de la etnografía: hacia la construcción de un modelo para trabajar sobre el terreno
}

\author{
David LoRENTE FERNÁNDEZ \\ Dirección de Etnología y Antropología Social, INAH (México) \\ david_lorente_fernandez@hotmail.com
}

Recibido: 2 de mayo de 2012

Aceptado: 16 de julio de 2013

\begin{abstract}
RESUMEN
Antes que ofrecer un modelo acabado, este artículo despeja algunas vías para establecer comparaciones etnográficas entre Mesoamérica y los Andes. Para ello, parte de las propuestas de ciertos mesoamericanistas y andinistas que han teorizado sobre dichas comparaciones basándose principalmente en materiales históricos, pero también recurre a estudios etnográficos realizados por investigadores de campo en ambas áreas con el objeto de ajustar la propuesta a procedimientos empíricos. El artículo explora la validez de utilizar conceptos nativos como categorías analíticas de utilidad para emprender trabajos comparativos.
\end{abstract}

Palabras clave: Comparaciones transculturales, metodología, etnografía, Mesoamérica, los Andes, ritualidad, cosmología.

\section{Comparing Mesoamerica and the Andes through Ethnography: Towards the Construction of a Model for Fieldwork}

\begin{abstract}
The aim of this article is not to present a finished model but to suggest different approaches for carrying out comparative ethnographic investigations between Mesoamerica and the Andean regions. It begins with theories that some Mesoamericanistas and Andeanists have developed based on their use of historical sources and adds what can be learned from ethnographic field investigations to make empirical comparisons between both regions. This article explores the validity of using native concepts which can be useful analytical categories to make such comparisons.
\end{abstract}

Key words: Cultural comparisons, methodology, ethnography, Mesoamerica, Andes, ritual, cosmology.

Sumario: 1. Introducción. 2. Las comparaciones mitológicas de Lévi-Strauss y algunas objeciones desde la etnografía. 3. Las propuestas histórico-contextuales de López Austin y Broda: desde México hacia el Perú. 4. El enfoque histórico-etnográfico de Luis Millones: del Perú hacia México. 5. Pero ¿qué métodos usar en el trabajo de campo? Hacia una etnografía intercultural comparativa. 6. Dos casos representativos de comparaciones etnográficas acotadas. 7. Hacia la propuesta. 8. Referencias bibliográficas.

\section{Introducción}

Hacia 1997, quizá antes, surge en los estudios sobre cosmologías indígenas un interés comparatista que parte de Mesoamérica y se dirige a los Andes ${ }^{1}$. Los textos de López Austin y Broda contenidos en el libro Pensar América de Garrido Aranda (1997) son una declaración de intenciones, y un esbozo metodológico para trabajar principalmente con fuentes históricas. Significativamente, tiempo después, en 2008, el peruano Luis Millones sugería un programa comparatista inverso -primero en colaboración con López Austin y después en solitario-, es decir, que partiendo de los

1 Entre los trabajos anteriores se encuentra, por ejemplo, el estudio etnohistórico de Limón Olvera (1990). 
Andes dirigía su mirada a Mesoamérica. Su propuesta completaba en espejo y desde el Sur, como una mirada cruzada, el interés surgido en Mesoamérica.

Pero tanto en el caso de las comparaciones mesoamericano-andinas como en el de las andino-mesoamericanas la etnografía, en cuanto método, es la gran ausente del panorama. Ninguno de los autores anteriores ofrece lineamientos u orientaciones sistemáticas para elaborar una etnografía comparativa entre ambas áreas. Por otro lado, pese a la multitud de monografías circunscritas a cada una de ellas por separado, y a los valiosos trabajos en coautoría donde cada especialista aporta su conocimiento sobre un área $^{2}$, lo cierto es que aún está pendiente la construcción de una propuesta que provea de orientaciones para llevar a la práctica comparaciones transculturales sobre el terreno.

El propósito de este artículo es, pues, brindar algunas vías metodológicas para establecer dichas comparaciones. No pretende ofrecer un modelo acabado, sino sugerir ciertas orientaciones para trabajar con la etnografía. Con tal fin examina los conceptos y enfoques de etnólogos que han realizado prolongadas investigaciones de campo en alguna de las dos áreas, y reflexiona sobre la pertinencia de utilizar conceptos nativos como categorías analíticas potenciales para emprender trabajos comparativos. Queda para más adelante, como una segunda fase de esta empresa, presentar un desarrollo más avanzado del modelo a partir de nuestras experiencias de campo y materiales etnográficos registrados en dos subregiones inscritas en estas macroáreas: una del centro de México y otra del sur del Perú ${ }^{3}$.

El ensayo se estructura como sigue. Primero revisa el método comparativo de Claude Lévi-Strauss, frente el que parecen reaccionar, implícitamente, los autores referidos al comienzo; después analiza las posturas de los mesoamericanistas y andinistas que han planteado recientemente enfoques comparativos, y finalmente, en sucesivos apartados, esboza la propuesta para llevar a cabo una comparación etnográfica sobre el terreno.

\section{Las comparaciones mitológicas de Lévi-Strauss y algunas objeciones desde la etnografía}

Hablar de comparaciones americanas implica referirse al monumental tratado de Lévi-Strauss formado por los cuatro volúmenes de las Mitológicas (2005a, 2005b,

\footnotetext{
2 Véanse, como ejemplos, tanto históricos como etnográficos, el artículo de Bernand y Gruzinski (1986) sobre los tipos de familia y el volumen de Galinié y Molinié (2006) acerca de los «neo indios».

3 Este artículo forma parte de una investigación más amplia en la que confluyen dos proyectos dirigidos por el autor en la Dirección de Etnología y Antropología Social del INAH, en México. Los materiales etnográficos sobre México proceden de la Sierra de Texcoco y están siendo recogidos desde junio de 2003; a partir de 2011 el trabajo de campo se realiza dentro del proyecto de investigación titulado «Medicina tradicional y lectura de la modernidad en la Sierra de Texcoco: nociones nahuas de cuerpo, curación y enfermedad ante la globalización» (INAH, $\mathrm{n}^{\circ}$ 3186). Algunos resultados figuran en Lorente (2010a, 2010b, 2011a, 2012a, 2012b, 2012c, 2012d). Los primeros materiales andinos fueron registrados gracias a una Beca Mixta Conacyt ( $\mathrm{n}^{\circ}$ 212204) y al convenio con el Centro Regional de Estudios Andinos 'Bartolomé de las Casas' en Cuzco, durante tres etapas: en enero de 2007; entre abril de 2008 y enero de 2009; y entre abril y junio de 2009. El trabajo de campo se realizó en las provincias cuzqueñas de Canchis (principalmente en la ciudad de Sicuani) y Canas (distrito de Checca), en el Sur del Perú. El estudio continúa actualmente en el marco del proyecto de investigación «Hombres del rayo y culto a los cerros en los Andes del Sur» registrado en el INAH (n $\left.{ }^{\circ} 6486\right)$. Véanse algunos resultados en Lorente (2010c, 2011b, 2013, s.f.).
} 
2005c, 2006), indispensable cuando se asume una perspectiva americanista. ¿Pero qué se compara en las Mitológicas y de qué forma? Lévi-Strauss parte de un vasto corpus de mitos que abarcan de Alaska a Tierra del Fuego. Su método es el siguiente. Los mitos recogidos por viajeros, misioneros o antropólogos son descompuestos en «mitemas» o unidades mínimas constitutivas y presentados como expresiones locales de un gran «sistema de transformación». Las combinaciones de personajes y motivos en episodios narrativos se descubren en grupos indígenas que no parecen tener conexión espacial entre sí, revelando, o sugiriendo más bien, la existencia de una unidad entre las culturas americanas. Esta macrounidad americana mostrada en los mitos permite, escribe Lévi-Strauss, que «entre unas [culturas] y otras [...] puedan postularse razonablemente vínculos reales de orden histórico o geográfico» (2001a: 11). «Actualmente -añade en Tristes trópicos-, después de los descubrimientos recientes y gracias, en lo que me concierne, a los años consagrados al estudio de la etnografía norteamericana, me doy cuenta de que el hemisferio occidental debe ser considerado como un todo» (1997: 275).

Pero el método comparativo estructuralista centrado en los mitos plantea diversos problemas.

En primer lugar, observamos que las Mitológicas son claramente descontextualizadoras. Los mitos, erigidos en metonimia de la cultura, son estudiados fuera de sus contextos culturales, abstraídos de la vida social interna de las comunidades a las que pertenecen y convertidos en «objetos autónomos». Para Lévi-Strauss las formas particulares de organización de los grupos productores de mitos pasan a segundo término. No importan tanto las significaciones particulares, pues lo relevante no está en «lo que los mitos tratan de explicar», sino en que son «aquello por medio de lo cual [...] tratan de explicar realidades que no son de orden natural sino lógico» (1994: 142). Los mitos constituyen modelos lógicos. Además, la metodología que concierne a las fuentes es problemática. Exceptuando los mitos procedentes de los indios bororo de Brasil y los de la orilla derecha del río Guaporé, recogidos por él mismo, todos los demás provienen de fuentes etnográficas y registros misioneros; los mitos fueron retraducidos al francés y resumidos atendiendo a su contenido argumental y temático. Así aparecen numerados y ordenados para mostrarlos «en sus relaciones recíprocas, como las partes instrumentales de una obra musical» (2001a: 35 ).

En este sentido, no extraña el rechazo de los antropólogos británicos coetáneos, más partidarios del trabajo de campo, por el método de Lévi-Strauss. Sus objeciones las recoge Leach diciendo: «[es muy difícil conciliar su postura] con el materialismo, el empirismo o cualquier otra actitud basada en los hechos observables» (1970: 4243). Leach censura a Lévi-Strauss el mostrar «una complacencia muy decimonónica en hablar de los mitos por sí mismos» y eludir su contexto social y el sentido de las manifestaciones particulares, cuyo significado no podía venir más que de un análisis del contexto (1970: 27-29). Según Leach, Lévi-Strauss confería autonomía a las formas ideológicas y les atribuía capacidad para explicar las estructuras sociales.

En suma, la descontextualización implica dos conclusiones. Por un lado, que las Mitológicas no dicen mucho sobre las culturas concretas en sí mismas. Por otro, según explica Johannes Neurath siguiendo a Preuss, que al no conocerse cada grupo específico ni «problematizarse la naturaleza de las relaciones entre las diferentes re- 
giones, no se logra apreciar la particularidad que tiene cada tradición étnica en el seno de este gran campo de estudios que es el continente» (2008: 10). El detalle cultural es sacrificado, pues, en pos de un nivel de comprensión más general.

Pero además de la descontextualización está el problema histórico (que bien visto, puede considerarse también un tipo de descontextualización a nivel temporal). La perspectiva comparativa de Lévi-Strauss es marcadamente ahistórica y obvia las condiciones diacrónicas de los grupos específicos: sus historias particulares, desarrollos y trayectorias pre y posthispánicas. Como afirma Gordon Brotherston en su libro $L a$ América indigena en su literatura: «Lévi-Strauss abordó en Mythologiques (19641971) el estudio de la América indígena tan sólo en el reino intemporal del estructuralismo, lavándose las manos, por así decirlo, del destino real de los sujetos humanos» (1997: 23). Esta perspectiva ahistórica se liga estrechamente, según Brotherston, a la definición estructural de «mito». En su artículo «The West and the People with Myths» (2002) afirma que la noción levistraussiana de mito alberga prejuicios etnocéntricos y que, oponiéndose a la tradición escrita occidental, sirve para situar a los pueblos con mitos al margen de la Historia, un argumento en parte semejante al de Eric Wolf (1987).

En tercer lugar está un problema asociado con las áreas culturales que interesan aquí. En lo que toca a nuestra propuesta, el método comparativo de Lévi-Strauss se encuentra geográficamente sesgado. Pese a señalar en varias ocasiones su interés por Mesoamérica y los Andes, y en concreto por México y Perú -escribe en Tristes Trópicos, por ejemplo, «las civilizaciones de México y Perú se comunicaron ciertamente en muchos momentos de su historia por el cabotaje a lo largo de la costa del Pacífico» (Lévi-Strauss 1997: 275) - ${ }^{4}$, la gran empresa continental omite ambas áreas culturales así como la pluralidad de grupos etnolingüísticos que contienen. ¿Por qué? Ambas áreas cuentan con una tradición histórica registrada en textos indígenas y coloniales y con una profusa vida ritual y ciclos mitológicos complejos. Además, comparten formas de producción y organización similares que no pueden obviarse en un estudio totalizador del continente. Es un vacío problemático por muchos motivos:

«en las críticas a las Mitológicas no se ha enfatizado suficientemente la exclusión injustificada de Mesoamérica y Perú, los dos focos de civilización agrícola americana. Esto resulta particularmente problemático al intentar establecer los complejos rituales y mitológicos asociados a las prácticas de cultivo» (Neurath 2008: 14).

Como el propio Lévi-Strauss señaló en alguna ocasión, su método comparativo no es fácilmente aplicable a este tipo de culturas con un desarrollo social tan intrincado y una formación estatal interétnica, lo que parece explicar esta curiosa omisión. Así pues, junto a la serie de problemas históricos y contextuales a los que nos hemos referido, existe un vacío en las Mitológicas de carácter temático y espacial, una especie

4 Por ejemplo, «las civilizaciones de México y Perú se comunicaron ciertamente en muchos momentos de su historia por el cabotaje a lo largo de la costa del Pacífico», dice en Tristes trópicos (1997: 275), y más adelante en la misma obra: «¿Habrá sido quizás en esta época [a principios del primer milenio antes de nuestra era] cuando las civilizaciones americanas comenzaron a distanciarse, asumiendo México y Perú la iniciativa y marchando a paso de gigante, mientras el resto se mantenía en una posición intermedia o se arrastraba hasta llegar a un estado semisalvaje?» (Lévi-Strauss 1997: 281-282). 
de gran «laguna» geográfica americana que concierne precisamente a las dos regiones culturales que nos competen aquí.

\section{Las propuestas histórico-contextuales de López Austin y Broda: desde México hacia el Perú}

En fechas recientes dos especialistas en Mesoamérica han planteado comparaciones entre las áreas mesoamericana y andina mediante enfoques teórico-metodológicos muy diferentes. Además de sugerir métodos en los que escuchamos ecos críticos respecto del enfoque anterior, sus comparaciones proponen un acercamiento que procede desde Mesoamérica hacia el Perú. Ambos defienden una comparación sistemática de las dos grandes áreas culturales centrada en tres ejes: la mitología, la cosmología y la vida ritual. Veamos con detalle sus perspectivas.

En un texto de 1997 consagrado al análisis de la mitología y la cosmovisión mesoamericana, López Austin destaca varios problemas que surgen al proponer una comparación con la región andina:

«la evaluación de las similitudes es un asunto complicado. ¿Se deben éstas a contactos entre los Andes y Mesoamérica? ¿Son paralelismos nacidos de la semejanza de las concepciones del ser humano cuando se encuentra en situaciones similares? ¿Provienen de un arcaico origen común americano y de un posterior desarrollo paralelo? ¿Nacen algunas de las prácticas y creencias tras la conquista, teniendo como fuente el pensamiento europeo? ¿Otras serán respuestas semejantes de las culturas indígenas ante la intrusión de conceptos europeos? Volvemos a muy viejas preguntas. La desgastada polémica entre el difusionismo y el paralelismo caducó antes de ser superada. Han quedado cuestiones pendientes. Más que desecharse, esta polémica debe ser replanteada con bases más sólidas y con un cuestionamiento más complejo» (López Austin 1997: 24).

El autor parte de la necesidad de replantear las razones de que existan semejanzas y diferencias, un planteamiento que va estrechamente asociado con la definición de una metodología diferente de la que se había venido utilizando. López Austin continúa:

«hay que proponer nuevos métodos para la evaluación de las semejanzas y diferencias entre ambas tradiciones. [...] Básicamente, mi propuesta es sencilla: analizar los rasgos en sus contextos social y cosmológico, de tal manera que no sean manejados como elementos aislados, sino como partes significantes de dichos contextos [...] ya que la evaluación de los rasgos fuera de su contexto es un camino demasiado inseguro. Existe el riesgo, por una parte, de tomar como reales semejanzas que sólo lo son en apariencia $\mathrm{y}$, por el contrario, no aquilatar la equivalencia de rasgos de apariencia diferente que cumplen iguales funciones en contextos cosmológicos afines. Aparte de esto, si no se toman en cuenta los contextos social y cosmológico, difícilmente se puede encontrar una razón de presencias y ausencias» (López Austin 1997: 24).

Este planteamiento metodológico, tan distinto del empleado como vimos por Claude Lévi-Strauss, no es sin embargo del todo nuevo en la historia de la Antropología. Diferentes autores preocupados por establecer comparaciones etnográficas han teo- 
rizado ya sobre varios de estos lineamientos ${ }^{5}$. La novedad, empero, y en esto tiene razón López Austin, consiste en aplicarlos específicamente al caso mesoamericanoandino. Las ideas principales son: no contemplar los rasgos que se van a comparar aisladamente sino en el seno de los contextos sociales y cosmológicos más amplios a los que pertenecen, donde ocupan una función concreta, y considerar que las seme-

\footnotetext{
5 Por ejemplo, y sin entrar en una digresión demasiado extensa, cabe destacar los estudios de cuatro autores principales: Konrad Theodor Preuss, Marcel Mauss, Radcliffe-Brown y Fred Eggan. Konrad Theodor Preuss, interesado en la reconstrucción de contactos entre culturas indígenas de México y del suroeste de los Estados Unidos, recomendó «circunscribir las comparaciones a regiones donde existe un parentesco lingüístico concreto o una acumulación de patrimonio cultural compartido» (citado en Alcocer 2008: 34), y determinó que se requiere, en lugar «de la comparación mecánica de inventarios de rasgos culturales aislados [...], profundizar en los estudios que posibiliten reflexionar sobre la coherencia causal interior de cada cultura. De cierta manera se trata de obtener una especie de pintura clásica, valorada en su autonomía, como un fin en sí misma» que, considerando particularidades y contextos, podría ser puesta en relación con otra cultura específica (citado en Alcocer 2008: 35). Marcel Mauss, por su parte, escribe sobre la metodología seguida en su análisis del don como sistema social total: «Hemos seguido un método comparativo concreto. Como siempre, hemos estudiado el tema en lugares determinados y elegidos: Polinesia, Melanesia, Noroeste americano, así como algunos derechos fundamentales [de las sociedades clásicas de Occidente]. A continuación, hemos elegido sólo aquellos derechos que, gracias a los documentos y a un trabajo filológico, ya que se trata de términos y nociones, nos daban acceso a la conciencia de la propia sociedad, lo cual ha limitado aún más el campo de comparaciones. Cada estudio nos ha conducido a un sistema que nos hemos ocupado de describir [...] en su integridad; renunciando [...] a una comparación constante donde todo se mezcla y donde las instituciones pierden su carácter local y los documentos su valor» (Mauss 1979 [1923-24]: 158, énfasis añadido). Radcliffe-Brown propuso también un método comparativo refinado: consideró que las escuelas anteriores -el evolucionismo de Morgan y Tylor y el difusionismo-, a las que él denominaba peyorativamente etnología, poseían un carácter especulativo, empleaban la reconstrucción histórica elaborando conjeturas sobre los orígenes, estaban interesadas en el análisis del desarrollo y los cambios culturales y usaban el método comparativo diacrónico, es decir, relacionando elementos culturales aislados -ya fuesen rasgos culturales o survivals- pertenecientes a grupos diversos y épocas históricas distantes, lo que ofrecía una imagen atomizada de la cultura. Frente a ellos, Radcliffe-Brown planteó adoptar el método inductivo de las ciencias naturales y emplear la comparación -ya no entre elementos fragmentados sino entre sistemas sociales totales- y la generalización en busca de leyes generales. En esta búsqueda fue riguroso a la hora de establecer contextos temáticos a los que debía ceñirse la comparación y consideró a las sociedades como sistemas integrados. Aunque eminentemente empírico, defendió el uso de documentos históricos siempre que éstos pudieran constatarse y validarse, y los consideró como un apoyo a la etnografía (véase El método de la antropología social [1975]). Finalmente, Fred Eggan, discípulo de Radcliffe-Brown en la Universidad de Chicago, planteó en su «Social Anthropology and the Method of Controlled Comparison» (Eggan 1954) una crítica de la postura particularista y anti-comparatista de Franz Boas, pero también del método de su maestro Radcliffe-Brown basado en las «comparaciones universales» a gran escala que le resultaban sospechosas. Recelaba de estas comparaciones generales destinadas a descubrir principios transculturales de la estructura social. Eggan revisó y afinó el método rechazando las grandes comparaciones en favor de lo que denominó «comparaciones controladas» (1954: 747). Su método era un producto genuinamente americano que combinaba el acercamiento del funcionalismo científico y el análisis transcultural con el enfoque histórico y procesual boasiano. Sus comparaciones, menos generalistas, eran a «pequeña escala» y procedían «with as much control over the frame of comparison at it is possible to secure» (1954: 747). Con esto criticaba el método de Radcliffe-Brown; después, aludiendo a Boas, añadía: «It has seemed natural to utilice regions on relatively homogeneous culture or to work within social or cultural types, and to further control the ecology and the historical factors so far at it is possible» (1954: 747). Eggan puso en práctica sus comparaciones controladas en la obra Social Anthropology of North American Tribes, de 1955, en la que estudió las terminologías de parentesco y los patrones de subsistencia de distintos grupos de las llanuras relacionando las diferencias entre los patrones de parentesco y subsistencia y las presiones adaptantes. En el artículo referido resumía los logros: su método permitía captar las «variaciones» de los diferentes tipos de parentesco de los indios Pueblo del Oeste como transformaciones de un tipo original y en el seno de un sistema regional (1954: 758). La idea de considerar contextos y de distinguir entre semejanzas formales y funciones profundas tiene, pues, una larga trayectoria en la historia de la antropología comparatista.
} 
janzas y diferencias no son cuestiones formales sino de la función que desempeñan en dichos contextos.

Tiempo después, López Austin y el investigador peruano Luis Millones llevan a cabo un intento comparativo, «aún inicial y preparatorio», en su libro titulado Dioses del Norte, Dioses del Sur. Religiones y cosmovisión en Mesoamérica y los Andes (2008). Allí presentan «en forma paralela, dos síntesis apretadas del pensamiento de ambas cosmovisiones», «dos trabajos independientes [...], en los cuales cada uno de los autores desarrolla el tema de su especialidad a su manera» (2008: 11). En él señalan aspectos metodológicos útiles para emprender la comparación:

«El estudio comparativo propuesto es de proporciones descomunales. La riqueza de las tradiciones mesoamericanas y andinas exige evaluación minuciosa de las fuentes, análisis profundos de cada una de las culturas particulares que las componen, estudios de su desarrollo temporal, conocimiento de las cosmovisiones de los pueblos indígenas de la actualidad [...]. Hemos abordado los temas de las cosmovisiones mesoamericana y andina como una provocación. Va dirigida a todos nuestros colegas; pero sobre todo a los jóvenes investigadores que, si aceptan el reto, ampliarán notablemente su enfoque científico» (López Austin y Millones 2008: 11).

Dos americanistas, uno especializado en Mesoamérica y otro en los Andes, manifiestan así la necesidad de desarrollar un planteamiento comparativo común.

También en 1997 Johanna Broda presenta un ensayo en el libro de Garrido Aranda Pensar América en el que plantea una comparación entre la ritualidad mexica e inca estudiando el paisaje ritual. Define su programa metodológico para analizar comparativamente Mesoamérica y los Andes en los siguientes términos:

«Desde la perspectiva mesoamericana, el material andino es sumamente interesante con referencia a los temas de la cosmovisión y la conceptualización de la naturaleza, por un lado, y por el otro con referencia a las funciones sociales y políticas de los ritos. [...] La comparación entre los cultos estatales mexica e inca, y los paisajes rituales creados por sendos imperios en sus áreas de influencia, [... también ilumina profundas semejanzas en cuanto a la concepción del mundo y los actos rituales. La combinación entre etnohistoria, arqueología y teoría antropológica nos permite reconstruir una imagen más completa del rompecabezas que constituyen las civilizaciones precolombinas» (Broda 1997: 66).

Más adelante precisa en cuanto al método, de manera similar a López Austin:

«[Sin embargo] ideología y cosmovisión no deben de estudiarse en abstracto sino como concreciones históricas de una cultura y un entorno geográfico específicos. [...] Para entender estos fenómenos hace falta manejar una visión de conjunto que ligue los aspectos materiales con los sociales y religiosos. Partiendo de esta perspectiva holística, resulta muy interesante comparar ciertos rasgos culturales [los ritos de petición de lluvia y sacrificios de niños, las ofrendas en miniatura, el culto a los cerros, al agua, la tierra y las deidades de la tormenta y el rayo, etc.] cuya articulación necesariamente tiene que mostrar variaciones importantes entre las culturas andinas y mesoamericanas» (Broda 1997: 67).

Después, en un texto de 2009, sintetiza su método. Parte de la propuesta de Gordon Brotherston (1997) sobre la existencia de una tradición indígena panamericana o «Tradición del Cuarto Mundo», con conceptos similares de espacio-tiempo, memoria política y relatos de creación, para trazar comparaciones diacrónicas entre ambas 
áreas culturales. La profundidad histórica, afirma, permite establecer comparaciones de rasgos semejantes a través del tiempo y de historias locales relativamente semejantes (Broda 2009: 78).

La novedad de su método estriba en basar la comparación andino-mesoamericana no en rasgos aislados, sino en «una serie de complejos conceptuales claramente estructurados que son significativos para estas culturas y han mantenido sus significados a través del tiempo» (Broda 2009: 79, énfasis añadido). Estos complejos se inscriben en el ámbito de la religión, la cosmovisión y la ritualidad indígena de Mesoamérica y los Andes, y consisten en:

«1.- El culto a los cerros, la tierra, las cuevas y el mar y sus rituales correspondientes. 2.- El culto a la lluvia y el simbolismo de los animales acuáticos, como las serpientes. 3.- Los ritos agrícolas del ciclo del maíz, íntimamente asociados con los fenómenos meteorológicos. 4.- El estudio de las ofrendas como un componente importante de los rituales indígenas y su compleja disposición en forma de cosmogramas» (Broda 2009: 79).

Dichos «complejos conceptuales estructurados» constituyen hilos conductores o ejes articuladores susceptibles de rastrearse histórica y etnográficamente. Además permiten afrontar la comparación como algo orgánico, pues las unidades de análisis son conjunto de rasgos con coherencia interna y no elementos culturales elegidos por sus semejanzas formales. Por último, los complejos conceptuales poseen una validez e independencia comprobadas en cada una de las regiones específicas que comprende el ejercicio comparativo.

\section{El enfoque histórico-etnográfico de Luis Millones: del Perú hacia México}

De forma coincidente con los planteamientos anteriores, el andinista Luis Millones analiza en dos libros -Todos los niños se van al cielo (2007) y Voces del limbo y el infierno en territorio andino (2010) - los mundos peruanos de los muertos recurriendo, en ocasiones, al material mesoamericano. Sin pretender realizar una comparación sistemática, se plantea utilizar de forma auxiliar, como útil contrapunto o «como telón de fondo, los estudios de religión mesoamericana, donde la información es más completa y la metodología ha sido explorada con detalle» (Millones 2007: 23). Su propósito es centrarse prioritariamente en el caso andino, y en este sentido añade, evaluando la producción y los estudios sobre los Andes: «estamos varios pasos atrás de lo que se ha logrado en Mesoamérica» (Millones 2010: 24-25). Lo interesante de sus libros es que ahora se trata de un estudioso de la religión andina quien decide dirigir su mirada hacia Mesoamérica. En ellos Millones describe la mortalidad infantil, la presencia de los niños fallecidos en la cosmovisión, los cultos a la lluvia, la fertilidad y el paisaje con fuentes históricas y etnográficas propias y ajenas.

En el prólogo a Voces del limbo y el infierno, Broda valora el enfoque interdisciplinar de Millones que combina la antropología con la historia, los procesos sincréticos y la inserción de las creencias en los marcos sociales, económicos y políticos. De manera interesante, nota la presencia de «complejos conceptuales» en el análisis comparativo de Millones: los niños muertos o angelitos se convierten en rayos y nubes que traen la lluvia en «un asombroso paralelismo con México» y concluye: «el 
libro constituye [...] una invitación a la comparación con Mesoamérica, planteando una sugerente pista de investigación» (Broda 2010: 17-18).

Félix Báez-Jorge, por su parte, escribe el epílogo del libro y aprovecha también para destacar los procedimientos metodológicos de Millones: el acercamiento histórico aplicado al estudio de la religiosidad popular y su relación con el culto católico, así como la reelaboración de los conceptos cristianos acerca del más allá, la idolatría, los infiernos y los demonios que aparecen analizados en sus complejos procesos de producción social y recreación simbólica. Resumiendo el enfoque de Millones, indica: «lo que en realidad nos ofrece este ensayo es un magnífico referente teórico y factual para trazar las líneas generales de un programa de investigación comparada, ciertamente urgente para el desarrollo de los estudios en torno a los procesos que caracterizan las tradiciones culturales en Mesoamérica y en el subcontinente andino» (Báez-Jorge 2010: 242).

\section{Pero ¿qué métodos usar en el trabajo de campo? Hacia una etnografía intercultural comparativa}

Surge ahora un problema acuciante: ¿cómo proceder con la etnografía?, ¿cómo tratar los datos empíricos? Nuestros propósitos son etnográficos. ¿Cómo obtener los datos sobre el terreno y cómo proceder para que resulten comparables? ¿Cómo registrar en Mesoamérica y los Andes información que sea coherente en sí misma y, a la vez, entre sí? Escasean los planteamientos sobre la manera de desarrollar empíricamente una etnografía comparativa en la literatura antropológica ${ }^{6}$.

Comencemos con un aspecto básico, al que ya se refería hace años RadcliffeBrown (1975): la siempre cuestionable legitimidad de las interpretaciones que el antropólogo extrae de los materiales recogidos por otros. Aunque se acepta con frecuencia que las comparaciones partan del registro del etnógrafo y que las referencias a otros lugares se hagan con materiales ajenos (véase por ejemplo Evans Pritchard 2006: 53-80), este modo de proceder resulta problemático. ¿Cómo evaluar la calidad y cómo manejar adecuadamente esta información que procede de otros autores? La práctica etnográfica comprende en sí misma multiplicidad de métodos, técnicas y enfoques. Cuando se comparan, por ejemplo, el Méthode de l'Ethnographie de Marcel Griaule, publicado en 1957, con el Manuel d'Etnographie de Marcel Mauss, que vio la luz en 1967, no es posible dejar de notar importantes divergencias. Pero si se revisan obras como el Notes and Queries (1971) británico, cuya última edición data de 1949, o el volumen -más reciente y perteneciente a la tradición norteamericanaEtnography, Principles in practice, de Hammersley y Atkinson (1983), la pluralidad de perspectivas etnográficas resulta asombrosa. No es posible ignorar la variedad de procedimientos y concepciones englobados bajo este término y el modo en que la etnografía ha evolucionado históricamente. Curándose en salud, y evitando una definición rígida, Hammersley y Atkinson indican: «Entendemos el término [etnografía]

6 Algunos estudios interesantes que tratan el tema de las comparaciones etnográficas son los de Ember and Ember (2001), Gingrich and Fox (2002) y González Echevarría (1991). 
como una referencia que alude principalmente a un método o conjunto de métodos» (2005: 15). El panorama se complica aún más al reconocer que la práctica y el resultado de la etnografía dependen además estrechamente de la formación, inclinaciones, posición política y hasta de la personalidad del propio observador (véanse, por ejemplo, Sheper-Hughes 1997; Rabinow 1992; Shostak 1987). Entonces, si se procede de la forma citada -es decir, recurriendo a materiales ajenos para establecer la comparación- no será fácil saber con certeza si las semejanzas o diferencias que extraemos del material ajeno al compararlo con el propio son por entero empíricas o resultado de las diferencias de enfoque y procedimientos adoptados por otros autores en otras áreas. En este sentido, concentrémonos en uno de los aspectos fundamentales de la obtención del material (que, como hemos señalado, son múltiples). El problema surge principalmente de la noción de «contexto».

Cuando el etnólogo reúne información de campo se ve obligado a delimitar de algún modo su contexto. Por lo general, el antropólogo sociocultural no se abocará a registrar datos aislados, al inventario de rasgos inconexos sobre religión, economía u organización social; más bien efectuará una suerte de «estudio de comunidad», quizá reducido, en el que pueda circunscribir el objeto analítico de su interés y captar las relaciones e interdependencias que éste sostiene con otros aspectos más generales de la cultura. Así, el tema de estudio será el resultado de un fenómeno, pero impregnado del resto de su contexto. Como indica Leach:

«En términos amplios, actualmente todos tenemos que aceptar el dogma funcionalista según el cual los detalles de una cultura deben observarse ‘en su contexto’. Pero ¿cuál es el límite del contexto? Funcionalmente hablando, todo está relacionado con todo lo demás y, en última instancia, cualquier cosa del universo resulta significativa. En la práctica, para escapar a este dilema, el antropólogo funcionalista limita arbitrariamente su contexto [...]. El antropólogo social no puede ser sociólogo, economista, psicólogo, historiador, etnógrafo y otras cosas más, todo a la vez; tiene que decidir dónde reside su centro de interés y ajustar sus métodos de investigación y descripción [...] El moderno investigador de campo [...], obsesionado con la necesidad de hacer comparaciones interculturales, ha tendido a especializar su curiosidad y estrechar su campo de visión» (Leach 1977: 15-16).

Al comparar, la etnografía debería determinar qué motivos culturales son importantes para las sociedades que relaciona y averiguar si la relación entre estos motivos y sus contextos son semejantes en ambas áreas. Es decir, la etnografía comparativa debe comparar motivos culturales y contextos. Una de las formas más adecuadas es sin duda mediante estudios de caso que persigan el conocimiento integral, o al menos lo más exhaustivo posible, de los respectivos contextos.

Surgen, pues, dos cuestiones. Primera, cómo seleccionar el objeto de estudio, es decir, ¿qué es importante para un grupo humano según las exégesis de los propios sujetos y el conocimiento etnológico e histórico que tenemos de él? Y segunda: persiguiendo la comparación, ¿es viable que un mismo investigador trabaje, con igual enfoque y modo de proceder, en dos grupos humanos y pueda así comparar etnográficamente los elementos afines y los contextos?

Sobre la primera pregunta -qué es relevante estudiar y cómo hacerlo-, ya nos hemos referido a la propuesta de López Austin de no «analizar los rasgos [...] como 
elementos aislados, sino como partes significantes de sus contextos» (1997: 24), y a la de Broda de tomar «complejos conceptuales claramente estructurados que son significativos para estas culturas» (2008: 79). Bajemos ahora el problema al terreno etnográfico y veamos cómo distintos autores, en estudios localmente circunscritos, han tratado de resolverlo sobre el terreno. Revisemos cuatro ejemplos, dos referidos a Mesoamérica (en concreto a México) y dos a los Andes (relativos a Perú y a Bolivia respectivamente), que servirán para avanzar en el desarrollo de la propuesta de una etnografía transcultural comparativa y para responder a la segunda pregunta.

Comencemos por México y el primer ejemplo. Ante la disyuntiva de cómo analizar coherentemente las creencias y ritualidad de los tlapanecos de la montaña de Guerrero, Danièle Dehouve no recurre a rasgos aislados sino a configuraciones significativas de elementos que guardan relación entre sí. ¿Qué rasgos de la cultura indígena forman complejos que pueden ser estudiados articuladamente y permiten a su vez iluminar el sentido de otros? Dehouve adopta el término de «unidades temáticas». Estas unidades, orgánicamente integradas, son productos culturales indígenas con estabilidad histórica y su estudio permite demostrar la continuidad prehispánica de ciertos elementos y la adopción, creativa, de otros nuevos en la «unidad». Lo explica detalladamente:

«Para evitar tal riesgo [el de considerar elementos aislados], conviene buscar la continuidad en las 'unidades temáticas', consideradas como conjuntos de elementos y conceptos, cuyo rastro se sigue en sus momentos históricos sucesivos [...]. Más que rasgos culturales relacionados o agrupados en conjuntos, es preciso buscar los principios estructurales de funcionamiento social que reglamentan los modos de actuar y de pensar. He propuesto ver en la unidad de los campos político y religioso en las poblaciones indígenas un principio de este tipo [...]. En efecto, [a la hora de investigar las unidades temáticas] una ventaja de la noción de principio reside en su carácter dinámico. La continuidad se expresa [no en los elementos propiamente dichos sino] en las reglas, las cuales debe descubrir el investigador y rigen la supervivencia de ciertos rasgos y la adopción de varios otros al mismo tiempo» (Dehouve 2007: 25-29).

Dehouve traza así un programa metodológico. La etnografía debe localizar «unidades temáticas» o conjuntos coherentes y articulados de elementos y conceptos que mantienen una continuidad histórica. Tras localizarlas, debe determinar su «principio estructural subyacente», es decir, la lógica cultural «que reglamenta los modos de actuar y de pensar» y que permite iluminar el funcionamiento, pervivencia y transformaciones de la unidad, la continuidad de ciertos rasgos y la inclusión de otros nuevos. Las «unidades temáticas» se asemejan a los «complejos conceptuales estructurados» de Broda, y en su funcionamiento interno están regidos por un principio similar a lo que López Austin (2001) llamó el «núcleo duro» de la cultura: una matriz estructurante que regula la coherencia interna y el dinamismo de la unidad.

Dehouve brinda un ejemplo de unidad temática, el «complejo Tlaloc». Este complejo reúne nociones sobre el señor de la lluvia, el cerro y los animales $-A j k u$ o San Marcos en el caso tlapaneco-, así como sus prácticas de culto, que tienen una notable profundidad histórica. El «complejo Tlaloc» logró asimilar a un personaje foráneo, San Marcos, en la unidad pues el campo semántico de este santo (la asociación con 
la lluvia) y las fechas rituales del calendario (su festividad responde a elementos pluviales) eran plenamente coincidentes con ella.

Pero ¿cómo rastrear sobre el terreno los principios estructurantes de la unidad, cómo registrarlos etnográficamente? Según Dehouve, partiendo de los discursos y exégesis nativos. Para estudiar una unidad, «le corresponde al antropólogo descubrir, en la sociedad que estudia, el contexto [sociocultural e histórico] y los principios» (2007: 32).

Un valor añadido de su metodología es que las unidades temáticas se corresponden a menudo con teorías indígenas - con concepciones nativas, emic-, pero también permiten trascenderlas y establecer discusiones teóricas relevantes para generar paradigmas etnológicos de mediano o largo alcance. Sin duda, y como se desprende de sus reflexiones, estas unidades temáticas son susceptibles de ser comparadas transculturalmente mediante la etnografía.

Segundo ejemplo. Congruente con la propuesta anterior, Catharine Good, al estudiar a los nahuas de río Balsas, en Guerrero, analiza los conceptos y prácticas indígenas combinados con la vida social de manera integrada. De acuerdo con las explicaciones de los nahuas, establece una serie de «ejes conceptuales» que revisten un carácter heurístico y permiten englobar grandes paquetes de fenómenos o lógicas culturales susceptibles de estudiarse no solamente entre los nahuas de Guerrero, sino en otras áreas indígenas de Mesoamérica. Estos «ejes conceptuales»

«consisten en: 1) un concepto muy complejo de trabajo o tequitl; 2) las relaciones de intercambio y reciprocidad que fundamentan la cosmología y la organización social; 3) un concepto de fuerza o energía vital que circula; 4) una clara conciencia de la continuidad histórica colectiva» (Good 2005: 87).

No es difícil encontrar en estos ejes conceptuales una clara homología con la propuesta de las unidades temáticas de Dehouve. Como sucedía con las unidades, el concepto de ejes conceptuales parte de una definición de «cultura» que vincula la organización social, el simbolismo y la vida ritual de manera articulada. La misma lógica cultural rige toda la vida indígena. «Un enfoque holístico [...] integra las relaciones económicas y la vida material con una cosmología activa en el mundo social» (Good 2004: 149). Los ejes ayudan a entender una pluralidad de dimensiones culturales, como la noción nahua de persona, la formación de grupos domésticos, la constitución de las comunidades y el conjunto de la región, el culto a los santos y a las entidades de la naturaleza, la concepción de la tierra como un ser que debe ser alimentado para que produzca y un largo etcétera. Explica Good:

«El valor explicativo del modelo propuesto reside en su capacidad para integrar distintas formas de organización social y diversas acciones colectivas dentro de un esquema interpretativo coherente. El modelo propuesto y los conceptos que lo conforman permiten entender y sintetizar muchos datos aparentemente dispersos y anecdóticos» (Good 2005: 104).

$\mathrm{Al}$ igual que en la propuesta de Dehouve, también Good plantea el diálogo entre teoría indígena y explicaciones etnológicas, y así crea un modelo inductivo y etnográfico de discusión teórica. «Los mismos datos de mi trabajo etnográfico -sostiene- me enfrentaron como investigadora con las fuertes limitaciones de las categorías analíticas tradicionales de la antropología para explicar las realidades empíricas documentadas 
en campo» (2005: 89). Así, la etnografía podía ayudar a la elaboración y afinación de categorías. Y de forma semejante a Dehouve, añade: «hay que conceptualizar los procesos de cambio como históricamente enraizados» en la antigua tradición mesoamericana, y no como simples fenómenos del presente; y por ello explica que su modelo de análisis es «histórico-procesual» (2005: 106). «Nuestra meta tiene que ser un concepto de cultura amplio, procesual, que permita estudiar el cambio pero que reconozca continuidad dentro del cambio» (Good 2004: 149).

Además, también ve una potencialidad comparativa en los ejes conceptuales. La comparación etnográfica debe seguir estos mismos ejes para considerar si se cumplen o no en otras sociedades. La comparación enriquecería los ejes al tiempo que iluminaría fenómenos similares, aunque quizá más ocultos, en otras áreas. Por ello concibe los ejes «como una propuesta que habría que explorar sistemáticamente en trabajos comparativos» (Good 2005: 87-88). ¿Podrían éstos ser transculturales? Si consideramos los ejemplos andinos que vienen a continuación, la respuesta podría ser seguramente afirmativa.

Tercer ejemplo, ahora andino. Sorprende que en la etnografía de los Andes se hallen acercamientos semejantes. En su estudio sobre la comunidad quechua de Sonqo, en el departamento de Cuzco, Perú, Catherine Allen indaga qué elemento o conjunto de rasgos son relevantes para los indígenas y permiten entender otros factores de la cultura. Su monografía, titulada originalmente The Hold Life Has [1988], fue traducida al castellano evocadoramente como La coca sabe: coca e identidad cultural en una comunidad andina (2008). Siguiendo el hilo conductor de la coca y su uso socioritual, Allen esclarece toda una serie de nociones relativas a la concepción quechua de la persona, la formación de lazos comunitarios, la configuración del espacio ritual, la cosmología centrada en los cerros y los procesos de cambio que produjeron disfunciones sociales y conflictos internos en el pueblo de Sonqo.

$\mathrm{Su}$ «complejo-coca» es muy semejante a las unidades temáticas de Dehouve y a los ejes conceptuales de Good. Parte de una visión unitaria de la cultura que fusiona las dimensiones individual, social, ritual y económica, el sistema de parentesco, la vida agrícola-pastoril, el culto colectivo y las ofrendas a la pachamama y los cerros en el contexto de la reciprocidad (y en ocasiones de la hostilidad) entre los seres del cosmos. Una vez más, las lógicas social, económica y simbólica aparecen imbricadas y se consideran indisociables y unificadas. Según Allen, el «complejo-coca» es indispensable para acceder etnográficamente al armazón de la cultura quechua. Escribe:

«Una invitación para masticar hojas de coca es una invitación a la interacción social. [...] el acto conjunto de masticar coca con otras personas, expresa el compromiso. [...] Lo ideal es que todos los $k$ 'intus [ramilletes de 3 hojas de coca] sean simétricos. [...] El grupo social está definido y organizado en torno a estos intercambios de $k$ 'intus, ya que la jerarquía social está implícita en el orden en el cual se ofrecen los k'intus [...] El compartir k'intus consolida una relación entre los compañeros que son parte del grupo al que uno pertenece [...] crea una relación entre el ser humano, la Tierra y los lugares sagrados» (Allen 2008: 154-155, 157).

«La reciprocidad es como un mecanismo de bombeo, en el corazón del cosmos circulatorio andino. [...] El intercambio de hojas de coca, acompañado por las invocaciones a las deidades, brinda una definición pacífica de la interacción social [...]. La coca, el leitmotiv que anuncia relaciones sociales armoniosas y la reciprocidad ritual con la tierra, ex- 
presa su particularidad cultural. El simbolismo ritual de las hojas de coca ejemplifica las premisas de la visión del mundo runakuna [quechua]. Vista desde una perspectiva histórica y sociopolítica más amplia, la coca también representa los cada vez más intensos dilemas de la ambigua situación cultural de los runakuna» (Allen 2008: 253, 260, 266).

La coca, para Allen, constituye el elemento unificador de la cultura andina; es un recurso relacional que permite formar grupos humanos a distintos niveles y vincular al hombre con la Tierra, los cerros y los lugares sagrados. La coca define el gran ciclo cósmico de intercambio, paradigma de la noción de vida en la ontología andina y de la identidad étnica quechua. Por ello los procesos culturales de continuidad y recreación dependen en gran parte del leitmotiv de la coca.

Partiendo de aquí, no resultaría improcedente tratar de trasladar el concepto de ejes conceptuales de Good al caso de Allen y ver en la coca una suerte de principio condensador de ejes conceptuales equivalentes al trabajo, los intercambios recíprocos, la energía vital que circula y la conciencia de continuidad histórica que Good propone para los nahuas. La comparación intercultural sería posible, analizando lógicas profundas y no únicamente rasgos formales. De igual modo, y de manera inversa, se podría trasladar a Mesoamérica el complejo-coca transformado en «complejo-maíz» para aplicarlo a los nahuas, y comprobaríamos así igualmente que la comparación transcultural resulta factible. Y otro tanto ocurriría si tomásemos el «complejo-coca» como una unidad temática andina -en el sentido de Dehouve-que mantiene su continuidad dinámica a lo largo de la historia.

El último ejemplo ahonda en el mismo sentido. Al estudiar a los aymaras kallawalla de la comunidad de Kaata, en Bolivia, Joseph Bastien adopta un recurso semejante y a la vez diferente. Para él, el motivo de interés que permite captar etnográficamente las dimensiones sociales y cosmológicas de la vida aymara es la «montaña». La montaña sagrada constituye el gran ordenador conceptual y ritual; es el operador analítico privilegiado para comprender las distintas dimensiones de la vida andina; la montaña es, afirma, una «metáfora» cultural omnipresente. Su libro, La montaña del cóndor: metáfora y ritual en un ayllu andino (1996), constituye un gran argumento en este sentido. Bastien explica:

«Para los kaateños, la montaña es la metáfora holística y unificadora. [...] Metafóricamente $[. .$.$] era concebida como un cuerpo humano con tres partes -cabeza, tronco$ y piernas. Los ritos agrícolas despertaban y alimentaban simbólicamente a la montaña para que la montaña fuera generosa con los kaateños y les otorgara alimento y vida [...]; a los kaateños se les ha hecho recordar la entereza de su montaña por medio de metáforas y ritos que otorgan [dotan] a las comunidades distantes y divididas de solidaridad cultural. [...] El simbolismo de la montaña de Kaata y sus ritos proporcionan una profunda comprensión de la sociedad andina y, por lo tanto, la montaña de Kaata podría tal vez ser llamada «la piedra angular de la cultura andina». [...] este libro intercala la comprensión metafórica de la montaña no sólo con los principios sociales sino también con los vínculos territoriales [es decir, que considera la conformación y definición del ayllu según el entendimiento indígena de la montaña]» (Bastien 1996: 19-20, 24).

Erigida en categoría central, la montaña aporta las claves para captar la concepción kallawalla de la persona y viceversa, ya que persona y montaña se corresponden. La metáfora-montaña da sentido a los ritos agrícolas (dedicados a alimentarla y a 
recibir alimento de ella) y permite entender el ciclo general de reciprocidad cósmica. Pero además, ayuda a vislumbrar la articulación entre las diversas comunidades y la constitución del territorio indígena, y en este sentido la montaña define espacialmente tanto el ayllu de Kaata como al conjunto de las poblaciones, proporcionando una definición de región. Así, la montaña integra en la misma unidad la mitología, la ritualidad y la organización económica y social, y por ello constituye «la piedra angular de la cultura andina». La montaña conjuga como metáfora todas las dimensiones de la vida andina, tanto diacrónica como históricamente, y por ello se asemeja no sólo al complejo-coca propuesto por Allen, con el que además resulta fácilmente articulable, sino a las unidades temáticas y los ejes conceptuales que ya se han descrito.

Resumiendo. Los cuatro casos examinados son coincidentes y permiten responder a la pregunta planteada: ¿qué es importante tanto para un grupo humano como para el investigador, y cómo estudiarlo? Los ejemplos ofrecen una respuesta: partiendo de un estudio de comunidad más extenso, se debe considerar la vida socio-cultural de manera integrada, captar los conceptos, complejos y principios subyacentes que permiten ordenar la pluralidad etnográfica y determinar si estos conceptos, complejos y principios son valiosos para los indígenas y la teoría etnológica. Las cuatro soluciones ofrecidas - «unidades temáticas», «ejes conceptuales», «complejos culturales» (complejo-coca) y «metáfora-montaña»- son muy valiosas. Surgen del conocimiento holístico de los contextos gracias a un análisis histórico y etnográfico. Además, y aunque a menudo aparece sólo sugerida, tras la formulación de estos conceptos analíticos los autores revelan una preocupación comparativa. Mientras Dehouve y Good sugieren que sus modelos son aplicables a otras regiones pertenecientes a la tradición cultural mesoamericana, Allen y Bastien hacen lo propio extendiendo los suyos a otras áreas (en realidad, a la totalidad) de los Andes. Pero la aplicación de los dos primeros modelos a los Andes y los dos últimos a Mesoamérica se plantea posible y fructífera. Los cuatro modelos son, pues, metodológica y temáticamente coherentes y complementarios, reconciliables.

¿Qué extraemos de esta revisión? Una metodología que sienta las bases para una etnografía comparativa. Partiendo de un estudio de caso en una región específica es posible acudir a una comparación sistemática con otra área para averiguar si las «unidades temáticas»o «ejes conceptuales» seleccionados existen también allí, captando las similitudes y diferencias de las unidades en sus respectivos contextos.

$\mathrm{Y}$ asumiendo esto estamos acercándonos a la segunda pregunta, derivada de la anterior: ¿es viable que un investigador trabaje con igual enfoque en dos áreas y pueda comparar así sus complejos temáticos y sus contextos? Seguramente. No obstante, son infrecuentes en la literatura americanista los trabajos etnográficos que emprenden comparaciones sistemáticas entre Mesoamérica y los Andes. Un caso interesante es el de John P. Gillin, quien, sin proponerse realizar una comparación de este tipo, escribe primero una monografía sobre una comunidad de la costa norte peruana, Moche (1947), y posteriormente otra sobre una comunidad guatemalteca, San Luis Jilotepeque (1958). Al redactar la segunda, recurre puntualmente a señalar ciertas similitudes entre las creencias de sus pobladores y las de los criollos de Moche, como la clasificación de los mismos alimentos en «calientes» y «frescos» (1958: 105, 1947: 53-54), o a servirse de las actitudes más bromistas de los pobladores de Moche para ofrecer 
un contraste con los de Jilotepeque (1958: 233). Pero el ejercicio no pasa de ahí. Para salvar esta escasez bibliográfica, es posible recurrir a una vía alterna y analizar cómo otros investigadores han llevado eficazmente a cabo comparaciones etnográficas transculturales no ya entre regiones de Mesoamérica y los Andes, como planteamos aquí, sino entre México y España, por un lado, y entre Perú y España, por otro. Se trata de los esfuerzos de un mesoamericanista y un andinista respectivamente, lo que resulta además relevante y significativo.

\section{Dos casos representativos de comparaciones etnográficas acotadas}

Esgrimiendo presupuestos metodológicos coincidentes con las unidades temáticas o los ejes conceptuales, James M. Taggart y José María Arguedas efectuaron en distintas épocas y con diferentes propósitos comparaciones etnográficas transculturales ofreciendo valiosos resultados.

El mesoamericanista James Taggart realizó un extenso trabajo de campo en la Sierra Norte de Puebla entre 1973 y 1984. Su investigación comenzó con un estudio sobre parentesco y organización social en dos comunidades nahuas vecinas: Huitzilan de Serdán y Santiago Yaonáhuac. Teniendo el contexto social de dos estudios de comunidad, pasó a analizar posteriormente, en una segunda fase, la forma en que la estructura social se reflejaba en la narrativa de carácter mítico, es decir, en los cuentos. En Nahuat Myth and Social Structure (1983) eligió una serie de narradores de ambos pueblos y reunió un corpus de relatos en náhuat ${ }^{7}$; los examinó a la luz de los roles de género masculinos y femeninos, los patrones de posesión de la tierra, la vida política, la posición jerárquica de los nahuas con relación a la de los mestizos y la interacción con los seres sobrenaturales. De estas comparaciones extrajo dos conclusiones. A nivel local, que en cada pueblo existían diferencias en la narración de los mismos relatos, pues las definiciones de los roles de género de los personajes variaban, por ejemplo, en función de si el enunciador era hombre o mujer y del momento o experiencia vital que atravesaba el narrador. A nivel regional, apreció que al comparar entre sí los mitos de los dos pueblos, Huitzilan de Serdán y Santiago Yaonáhuac, surgían diferencias más generales que traducían la estructura social y la historia particular de cada una de las comunidades. Concluyó:

«Comparison of parallel stories has illustrated a number of consistent differences between the narratives from the two communities. Narratives from Huitzilan and Yaonáhuac have developed two variants of a common cultural model in accord with changes Hispanics have brought to their social structure» (Taggart 1983: 202).

Conocer los contextos socio-históricos locales y regionales en los que se inscribían los relatos le permitió a Taggart emplear estas narraciones como una especie de ventanas o instrumentos reveladores privilegiados de la cultura. Los mitos o cuentos populares formaban algo así como unidades temáticas susceptibles de comparación.

Una vez comprobada la utilidad del recurso, Taggart se propuso un estudio más ambicioso. ¿Cuál era el contenido de las historias en su contexto original? ¿Cómo

7 La variante lingüística de esta zona se denomina «nahuat», pues carece de la «tll» final. 
se plasmaban la estructura social y los roles de género en los cuentos españoles, que eran los modelos originales de los que procedían los relatos que narraban hoy en día los nahuas? ${ }^{8}$ Entre 1980 y 1984, explica, «I went to Spain to find out how storytellers represented themselves in a different, Castilian Spanish narrative style. Published collections of folktales would not do for this purpose because they provide almost no information about the narrators» (1997: 7, énfasis añadido). Surgía un problema metodológico: no era viable efectuar la comparación acudiendo a las compilaciones de cuentos españoles existentes, pues éstas omitían el contexto y no aportaban información detallada sobre las comunidades de las que procedían los cuentos ni sobre los narradores.

¿Cómo realizar entonces una comparación legítima? Únicamente trasladándose a España y recopilando él mismo el material, lo que hizo siguiendo el mismo procedimiento etnográfico con el que había actuado en México. Adecuó la metodología que había desarrollado en Puebla a las condiciones locales de una comunidad de Extremadura, Navaconcejo, al norte de la provincia de Cáceres. Pero ¿por qué Extremadura? Su decisión respondía al presupuesto de que de esta región habían partido la mayoría de los conquistadores españoles llevando consigo los cuentos populares a México, y concretamente a la Sierra Norte de Puebla. Instalado en Navaconcejo, efectuó registros etnográficos sobre el terreno y recurrió a la observación participante y a las entrevistas en profundidad con vecinos y narradores acreditados. Con su «folktale comparative method» (1997: 2) quiso averiguar cómo los extremeños representaban y reproducían los roles de masculinidad, el concepto de persona y las relaciones con los otros seres del cosmos, y en qué medida todas estas concepciones diferían de las que los nahuas plasmaban en los mismos cuentos españoles traducidos a su cultura.

Como unidades de análisis para la comparación, eligió una serie de cuentos muy conocidos y también ciertos motivos narrativos que eran recurrentes en ambas áreas. Del acervo reunido en México y España seleccionó los cuentos «Juan Oso» o «El oso y sus hijos», «Hermanos de sangre», «Los dos viajeros», «Blancaflor» y «Orfeo», así como algunos sobre personajes burlones o «tricksters». En su análisis yuxtapuso las versiones española y nahuat de cada cuento e incluyó las respectivas indicaciones sobre el contexto necesarias para establecer la comparación. En las narraciones se reconocían ciertas semejanzas argumentales o formales, pero afloraban patrones sociales y nociones culturales muy diferentes. Si en Extremadura, por ejemplo, el hombre aparecía como un sujeto, un «individuo» que podía actuar en el mundo de forma aislada y servirse a veces de la agresividad para reivindicar su independencia y autonomía, entre los nahuas de México la interdependencia generalizada definía el modo adecuado de conducirse en los ámbitos familiar, comunitario y con los seres sobrenaturales. Esto se plasmaba, lógicamente, en las respectivas cosmologías. Mientras en Extremadura los seres sobrenaturales se desenvolvían con libertad y de forma amoral en un mundo dominado por el diablo como entidad suprema que tentaba a los hombres, entre los nahuas existía «a highly connected cosmovision in wich humans are connected to animals, spirits interfere in human affairs, and death only transforms but does not sever ties among human beings» (Taggart 1997: 245-246). Dos tipos di-

8 Véase, sobre este aspecto, una exposición más detallada en Taggart (1988). 
ferentes de estructura social y sistemas cosmológicos eran revelados por los mismos cuentos. Mediante adaptaciones locales, constituían síntesis que reflejaban la articulación y relaciones recíprocas de numerosos rasgos de la cultura. En su variante de «historias paralelas» (parallel stories), los cuentos mostraban una enorme potencialidad como recurso para establecer comparaciones a través de la etnografía transcultural.

En cuanto al andinista José María Arguedas, escritor y etnólogo peruano, su método es en parte coincidente. En 1957 se había consolidado como especialista en los Andes con su tesis de bachiller La evolución de las comunidades indígenas (1957a). Tanto en sus novelas y cuentos de inspiración etnográfica (véanse 1935, 1941, 1958, 1971, 1974), como en los numerosos artículos y ensayos publicados durante su desempeño como folklorista y docente, había analizado la realidad andina minuciosamente y desde el interior ${ }^{9}$. Su vastísimo campo de interés abarcó una inmensidad de temas como las canciones, poesías y cuentos populares en lengua quechua (1949, $1953,1957 b)$, las fiestas y ceremonias de siembra y cosecha, los rituales de carácter identitario, la cerámica tradicional, las ferias, los carnavales, los ritos de matrimonio, el sistema de autoridades tradicionales, los curanderos y brujos, la lingüística quechua, las relaciones entre indígenas y mestizos, etcétera, por citar sólo algunos ejemplos ${ }^{10}$. Sus análisis acerca de la comunidad andina, sus características de organización, economía, religión y dinámica de cambio y continuidad fue recogida en dos textos principales: un artículo de 1957 relativo al departamento de Junín, próximo a Lima, titulado «Evolución de las comunidades indígenas (Valle del Mantaro)», y un ensayo etnográfico clásico de 1956, «Puquio, una cultura en proceso de cambio».

Partiendo de este conocimiento acumulado, en 1962 Arguedas se propuso como tesis doctoral establecer una comparación con las comunidades españolas de la región de Castilla-León y Extremadura; su tesis se tituló Las comunidades de España y del Perú (1968). Gracias a una beca de la Unesco viajó a la Península para realizar su trabajo de campo de seis meses de duración en dos pueblos, uno castellano y otro extremeño. Describe así su programa comparativo:

«[Pretendíamos] realizar nuestra vieja aspiración de estudiar algunas comunidades de España con el objeto de buscar en la actual organización de esas comunidades datos complementarios para el mejor conocimiento de la historia de las comunidades indígenas del Perú. Confiábamos en que encontraríamos en España, especialmente en Castilla y Extremadura, supervivencias de muy antiguas formas de organización comunal; y que el buen conocimiento de esas supervivencias y de sus fundamentos históricos iluminarían la historia y la realidad actual de la organización y funcionamiento de nuestras comunidades, lo que sus instituciones representan como productos del pasado y como partes integrantes de nuestra actual e intrincada composición social.

Nuestra fe estaba fundada en el hecho comprobado de que España es uno de los países menos evolucionados de Europa y que, por tanto, las supervivencias tenían que ser allí mayores y más íntegras. Por otro lado, estaba asimismo demostrado que la política colonial aprovechó hábilmente y hasta donde fue posible tanto las formas de

\footnotetext{
9 Véase al respecto el ensayo de Mario Vargas Llosa (1996) La utopía arcaica. José María Arguedas y las ficciones del indigenismo.

10 Véase la ingente recopilación de artículos de los años 40 contenida en el volumen Indios, mestizos y señores (Arguedas 1989).
} 
organización social del antiguo Perú como las de España. Y que tales formas se integraron o ensamblaron no sólo por obra de los gobernantes sino de la práctica cotidiana de las ordenanzas, de su interpretación por el colonizador y de su acierto para explotar la antigua organización indígena en su beneficio.

Luego de nuestra breve permanencia, en tres pueblos de Castilla, algunos aspectos de la historia social del Perú se nos presentaron como problemas que podían ser mejor esclarecidos, y pudimos quedar convencidos de la utilidad del trabajo [comparativo] que realizamos» (Arguedas 1968: 7).

Finalmente eligió dos pueblos - Bermillo de Sayago y La Muga, ambos en Zamora, Castilla-León- siguiendo la lectura de la obra de Joaquín Costa, y estructuró su tesis con las entradas tradicionales de las monografías clásicas. La primera parte, dedicada a Sayago, describe la economía (propiedad, agricultura, ganadería, artesanía, etc.), la estructura social básica (familia e infancia), la estructura social del grupo (estratificación, movilidad social, migraciones, etc.), el gobierno comunal y la política (ayuntamiento, servicios comunales, poder político, clero, religión, congregaciones y fiestas), la educación y la cultura intelectual (escuela, teatro y biblioteca, etc.). Cada sección se acompaña de un epígrafe final en el que introduce la comparación con Perú, desarrollando algunas observaciones etnográficas sobre los Andes que sirven para destacar similitudes y diferencias. La segunda parte del libro, consagrada a La Muga, recupera, de forma más breve, estas entradas e incluye igualmente comparaciones puntuales con Perú.

En la tercera parte, más conclusiva, Arguedas efectúa la comparación sistemática que da nombre a su tesis. Sintetiza los resultados por apartados -Economía, Política, Estructura social, Religión, Educación, Dinámica y Valores-. Procede de la siguiente manera: traslada lo encontrado en España a la situación en el momento de la Conquista y lo compara con la organización actual del ayllu andino basado en la minka y el ayne (el trabajo comunal guiado por la reciprocidad), las formas quechuas de organización y parentesco, el culto a los cerros sagrados (wamanis) frente la religión católica española y la educación indígena andina frente a la colonial (Arguedas 1968: 329-347).

De manera similar a la de Taggart en su comparación entre cuentos tradicionales de México y España, Arguedas defiende la utilidad de recurrir al concepto de «comunidad rural» a la manera de unidad temáticaa como recurso que presenta, de forma imbricada y en cada país, formas de vida social históricamente consolidadas. La propuesta inicial perseguía captar «qué había de España en Perú», según sus propias palabras, pero el resultado ofrecía un panorama más englobante al abarcar diferentes rasgos culturales de la vida local que eran comparados sistemáticamente. El énfasis en las comunidades le permitió desplegar todos los elementos que había analizado en sus estudios etnográficos peruanos, y retomar sus diferentes trabajos sobre Puquio, Cuzco y el Valle del Mantaro para contrapuntear la información castellana. Como apunte final, y basándose en la información del presente (1964), trató de predecir la situación futura de las «comunidades» en ambos países. Sometidas, dice Arguedas, a la presión de Estados modernizadores que no ven en la vida campesina sino un freno al desarrollo, España y Perú parecen perseguir que sus áreas rurales «detenida[s] en su desarrollo histórico» se transformen «en pequeñas sociedades de tipo liberal» 
(1968: 345-346). La comparación se cierra, así, incluyendo la relación de las comunidades con el entorno político y sus dinámicas históricas de cambio forzado.

\section{Hacia la propuesta}

Desde una panorámica general, descubrimos numerosas similitudes en las obras y perspectivas de Taggart y Arguedas. Ambos investigadores se interesan por la adaptación local de elementos e instituciones peninsulares (extremeñas y castellanas) a grupos amerindios nahuas y quechuas respectivamenten, analizan los procesos de recreación histórica y las raíces culturales compartidas por ambas áreas. Pero lo relevante para nuestra propuesta es la manera en que ambos aportan una metodología comparativa precisa basada en la etnografía. Su manera de proceder es la siguiente. Primero realizan un estudio de comunidad intensivo en el área cultural de partida u origen y así logran determinar qué elemento o unidad temática articula la cultura local a través del conocimiento de su contexto. Después eligen otra área cultural de acuerdo con su problema analítico y realizan un nuevo estudio de caso para comprobar si la primera unidad temática es susceptible de comparación considerada en otro contexto. Con este método parten de la etnografía sobre el terreno pero recurren también a la historia y a una perspectiva analítica de larga duración. Por último proceden descomponiendo su unidad temática en rasgos interrelacionados y los comparan tanto separada como unificadamente, alcanzando un resultado sistemático. El mismo investigador recoge información en dos áreas con la misma formación y aproximación metodológica para establecer parámetros definidos y acotar y controlar al máximo posible la comparación intercultural.

Considerando diferentes objetos de estudio, que pueden ser definidos de diversas formas, y centrando la comparación entre Mesoamérica y los Andes a través de la etnografía, éste es seguramente el modo más adecuado de proceder y el que ofrece visos de resultar metodológicamente más fructífero, pues atestigua que es posible «trasladar» las unidades temáticas de un área cultural a otra de manera rigurosa y empírica. Los ejemplos referidos a Mesoamérica, por un lado, y a los Andes, por otro, y los que comparan aspectos de estas dos áreas culturales con elementos españoles, así parecen demostrarlo.

\section{Referencias bibliográficas}

AlCOCER, Paulina

2008 «Lucha cósmica y agricultura del maíz: la etnología comparativa de K. T. Preuss», en Por los caminos del maíz. Mito y ritual en la periferia septentrional de Mesoamérica, Johannes Neurath, coord., pp. 30-84. México: Fondo de Cultura Económica - Conaculta.

Allen, Catharine

1988 The Hold Life Has. Coca and Cultural Identity in an Andean Community. Washington: Smithsonian Institution Press.

2008 La coca sabe. Coca e identidad cultural en una comunidad andina. Cuzco: Centro de Estudios Regionales Andinos 'Bartolomé de las Casas'. 
Arguedas, José María

1935 Agua. Los escoleros. Warma Kuyay. Lima: Compañía de Impresiones y publicidad [versión consultada 2005 Agua y otros cuentos. Lima: Biblioteca de Literatura Peruana].

1941 Yawar Fiesta. Lima: Compañía de Impresiones y Publicidad [versión consultada: 2003 Biblioteca de Literatura Peruana].

1949 Canciones y cuentos del pueblo quechua. Lima: Editorial Huascarán.

1953 «Cuentos mágico-realistas y canciones de fiestas tradicionales del valle del Mantaro, provincias de Jauja y Concepción». Folklore Americano 1: 101-293.

1956 «Puquio, una cultura en proceso de cambio». Revista del Museo Nacional 26: 184-232.

1957a La evolución de las comunidades indígenas, Tesis de Bachiller en Etnología. Lima: Universidad Nacional Mayor de San Marcos.

1957b «Evolución de las comunidades indígenas. El valle del Mantaro y la ciudad de Huancayo: un caso de fusión de culturas no comprometida por la acción de las instituciones de origen colonial». Revista del Museo Nacional 26: 78-151.

1958 Los ríos profundos. Buenos Aires: Editorial Losada [edición consultada: 2003 Biblioteca de Literatura Peruana, Lima].

1968 Las comunidades de España y del Perú. Lima: Universidad Nacional Mayor de San Marcos.

1971 El zorro de arriba y el zorro de abajo [novela póstuma]. Buenos Aires: Editorial Losada.

1974 Relatos completos. Buenos Aires: Editorial Losada.

BÁEz-Jorge, Félix

2010 «Epílogo. Ángeles y demonios en el mundo simbólico de los desposeídos», en Voces del limbo y del infierno en territorio andino, Luis Millones, pp. 242-280. Veracruz: Editora de Gobierno del Estado de Veracruz.

BASTIEN, Joseph

1996 La montaña del cóndor: metáfora y ritual en un ayllu andino [1978]. La Paz: Hisbol.

BRODA, Johanna

1997 «Tallado en roca, ritualidad y conquista mexica e inca: una comparación», en Pensar América. Cosmovisión mesoamericana y andina, Antonio Garrido Aranda, comp., pp. 46-73. Córdoba: Cajasur - Ayuntamiento de Montilla.

2009 «Historia comparada de las culturas indígenas de América», en El historiador frente a la Historia. Historia e historiografía comparadas, Alicia Mayer, coord., pp. 75-100. México: IIH - UNAM.

2010 «Prólogo», en Voces del limbo y del infierno en territorio andino, Luis Millones, pp. 7-21. México: Editora de Gobierno del Estado de Veracruz.

BRotherston, Gordon

1997 La América indígena en su literatura: los libros del cuarto mundo. México: Fondo de Cultura Económica.

2002 «The West and the People with Myth», en Myth. A New Symposium, Gregory Schrempp y William Hansen, eds., pp. 139-148. Bloomington: Indiana University Press.

Dehouve, Danièle

2007 La ofrenda sacrificial entre los tlapanecos de Guerrero. México: Plaza y Valdés INAH.

EGGAN, Fred

1954 «Social Anthropology and the Method of Controlled Comparison». American Anthropologist 56 (5, parte 1): 743-763. 
1955 Social Anthropology of North American Tribes. Chicago: University of Chicago Press.

EMber, Carol R. y Melvin EMBER

2001 Cross-Cultural Research Methods. Walnut Creek: Altamira Press.

EvANS-PRITCHARD, E. E.

2006 «Historia y Antropología», en Ensayos de antropología social [1962], pp. 53-80. Madrid: Siglo XXI.

GALINIER, Jacques y Antoinette Molinié

2006 Les néo-Indiens. Une religion du IIIe millénaire. París: Odile Jacob.

GiLlin, John P.

1947 Moche. A Peruvian coastal community. Washington: Smithsonian Institution, Institute of Social Anthropology.

1958 San Luis Jilotepeque. La seguridad del individuo y de la sociedad en la cultura de una comunidad guatemalteca de indígenas y ladinos. Guatemala: Editorial del Ministerio de Educación Pública.

Gingrich, Andre and Richard G. Fox (eds.)

2002 Anthopology, by comparison. Cambridge: The University Press.

GonzÁlez Echevarría, Aurora

1991 Etnografía y comparación. La investigación intercultural en antropología. Barcelona: Universitat Autónoma de Barcelona.

Good, Catharine

2004 «La vida ceremonial en la construcción de la cultura: procesos de identidad entre los nahuas de Guerrero», en Historia y vida ceremonial en las comunidades mesoamericanas: los ritos agrícolas, Johanna Broda y Catharine Good Eshelman, coords., pp. 127-149. México: INAH - UNAM.

2005 «Ejes conceptuales entre los nahuas de Guerrero: expresión de un modelo fenomenológico mesoamericano». Estudios de Cultura Náhuatl 36: 87-113.

GruZinski, Serge y Carmen Bernand

1986 «Les enfants de l'Apocalypse: la famille en Méso-Amérique et dans les Andes», en Histoire de la famille, T.III: Le choc des modernités, André Burguière, dir., pp. 205-279. París: Armand Colin.

Hammersley, Martyn y Paul Atkinson

1983 Etnography. Principles in practice. Londres: Routledge.

2005 Etnografía. Métodos de investigación. Barcelona: Paidós.

LEACH, Edmund

1970 Lévi-Strauss, antropólogo y filósofo. Madrid: Anagrama.

1977 «Introducción», en El cultivo de la tierra y los ritos agrícolas en las Islas Trobriand. Los jardines de coral y su magia. Primera parte, Bronislaw Malinowski, pp. 9-18. Barcelona: Labor.

LÉvi-Strauss, Claude

1994 El pensamiento salvaje [1962]. México: Fondo de Cultura Económica.

1997 Tristes trópicos [1955]. Barcelona: Paidós.

2005a Mitológicas I. Lo crudo y lo cocido [1968]. México: Fondo de Cultura Económica. 2005 b Mitológicas III. El origen de las maneras de mesa [1970]. México: Siglo XXI.

2005c Mitológicas II. De la miel a las cenizas [1972]. México: Fondo de Cultura Económica. 
2006 Mitológicas IV. El hombre desnudo [1976]. México: Siglo XXI.

Limón Olvera, Silvia

1990 Las cuevas y el mito de origen. Los casos inca y mexica. México: Conaculta.

López Austin, Alfredo

1997 «Tras un método de estudio comparativo entre las cosmovisiones mesoamericana y andina a partir de sus mitologías», en Pensar América. Cosmovisión mesoamericana y andina, Antonio Garrido Aranda, comp., pp. 19-43. Córdoba: Cajasur Ayuntamiento de Montilla.

2001 «El núcleo duro, la cosmovisión y la tradición mesoamericana», en Cosmovisión, ritual e identidad de los pueblos indígenas de México, Johanna Broda y Félix BáezJorge, coords., pp. 47-65. México: Conaculta - Fondo de Cultura Económica.

López Austin, Alfredo y Luis Millones

2008 Dioses del Norte, dioses del Sur. Religiones y cosmovisión en Mesoamérica y los Andes. Lima: Instituto de Estudios Peruanos.

LORENTE FERnÁNDEZ, David

2010a «Trayectoria metodológica de una investigación etnográfica en México». Revista Española de Antropología Americana 40 (1): 85-110.

2010b «El remolino actuado: etnografía contemporánea del Monte Tláloc». Revista de Dialectología y Tradiciones Populares, 65 (2): 519-546.

2010c «3-cerro y 4-mundo: los números del banquete en las ofrendas quechuas». Anthropologica 28 (28): 163-190. Lima.

2011a La razzia cósmica: una concepción nahua sobre el clima. Deidades del agua y graniceros en la Sierra de Texcoco. México: CIESAS - UIA.

2011b «La violencia del Estado como chiaraje o guerra ritual: una interpretación cosmológica de la lucha del ejército contra los quechuas de Sicuani en el sur del Perú». Revista Española de Antropología Americana 41 (2): 547-554.

2012a «El 'frío' y el 'calor' en el sistema médico nahua de la Sierra de Texcoco. Una aproximación». Revista Española de Antropología Americana 42 (1): 251-260.

2012b «Nezahualcóyotl es Tláloc en la Sierra de Texcoco: historia nahua, recreación simbólica». Revista Española de Antropología Americana 42 (1): 63-90.

2012c «Ser respetuoso es ser persona. El niño y la pedagogía moral de los nahuas del centro de México». Revista de Dialectología y Tradiciones Populares 67 (2): 431-452.

2012d «Amores de manantial. Un episodio nahua de curación en la Sierra de Texcoco». Tlalocan. Revista de fuentes para el conocimiento de las culturas indígenas de México, vol. XVIII: 179-200.

2013 «Apu Jururu: presidente, médico y justicia. Rituales y simbolismo de un monte sagrado del sur de Perú», en América, Tierra de Montañas y Volcanes, Margarita Loera Chávez y Peniche, Stanislaw Iwaniszewski y Ricardo Cabrera, coords. México: INAH - Conaculta.

s.f. «Pájaros en la oscuridad. Entre lo nocturno y lo diurno en las ceremonias de llamada a los apus del sur del Perú».

Mauss, Marcel

1974 Introducción a la Etnografía [1967]. Madrid: Ediciones Istmo.

1979 «Ensayo sobre los dones. Motivo y forma del cambio en las sociedades primitivas» [1923-24], en Sociología y Antropología, pp. 153-263. Madrid: Tecnos.

Millones, Luis

2007 Todos los niños se van al cielo. Lima: Publicaciones del Instituto Riva-Agüero. 
2010 Voces del limbo y del infierno en territorio andino. México: Editora de Gobierno del Estado de Veracruz.

NeURATH, Johannes

2008 «Introducción», en Por los caminos del maíz. Mito y ritual en la periferia septentrional de Mesoamérica, Johannes Neurath, coord., pp. 9-29. México: Fondo de Cultura Económica - Conaculta.

Notes and Queries on Anthropology

1971 Manual de campo del antropólogo (Versión española del Notes and Queries on Anthropology preparada por Carmen Viqueira, Ángel Palerm y Luis Olivos por encargo de la Unión Panamericana). México: Editorial Comunidad - Instituto de Ciencias Sociales.

RABINOW, Paul

1992 Reflexiones sobre un trabajo de campo en Marruecos. Madrid: Júcar.

RADCLIFFE-BRown, A. R.

1975 El método de la antropología social [1958]. Barcelona: Anagrama.

ScHePER-Hughes, Nancy

1997 La muerte sin llanto. Violencia y vida cotidiana en Brasil. Barcelona: Ariel.

SHOSTAK, Marjorie

1983 Nisa: The life and words of a ;kung woman. New York: Random House.

TAGGART, James

1983 Nahuat Myth and Social Structure. Austin: University of Texas Press.

1988 «Asimilación de cuentos españoles en la tradición oral de los nahuas de México», en Mito y ritual en América, Manuel Gutiérrez Estévez, ed., pp. 138-174. Madrid: Editorial Alhambra.

1997 The Bear and His Sons: Masculinity in Spanish and Mexican Folktales. Austin: University of Texas Press.

VARgas Llosa, Mario

1996 La utopía arcaica. José María Arguedas y las ficciones del indigenismo. México: Fondo de Cultura Económica.

Wolf, Eric

1987 Europa y la gente sin historia. México: Fondo de Cultura Económica. 